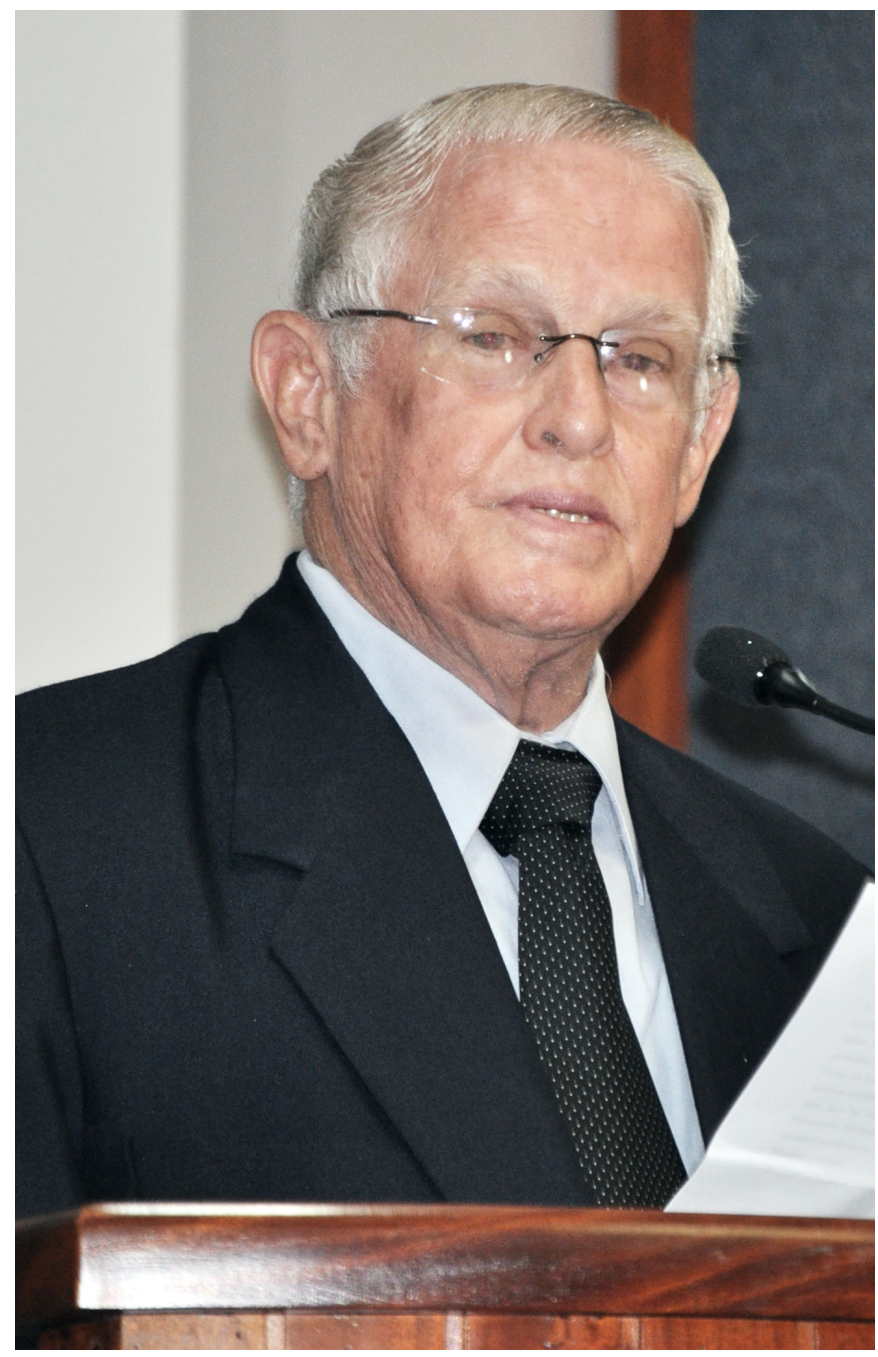

\title{
Entrevista al profesor Dinápoles Soto Bello
}

\author{
Profesor emérito de la PUCMM, \\ premio "Laudatio academica" \\ otorgado por la Academia \\ de Ciencias de la República \\ Dominicana.
}

\section{6}

a enseñanza ha de focalizarse en principios y razonamientos en todas las actividades de formación del estudiante: resolución de problemas para afianzar la base teórica, prácticas de laboratorio para desarrollar destrezas experimentales, exposiciones orales y escritas para desarrollar habilidades comunicacionales e investigación para cultivar y "vivenciar" la ciencia".

¿Cómo inicia su trayecto en la PUCMM y a qué atribuye su crecimiento permanente en nuestra Universidad?

En el verano del año 1969 empecé a dar clases en la UCMM, luego de dos años de experiencia docente en la Universidad Autónoma de Santo Domingo (UASD), donde me contrataron con dedicación exclusiva al regresar al país luego de completar una licenciatura en ciencias físico-matemáticas en el Instituto Tecnológico y de Estudios Superiores de Monterrey (ITESM), México.
El crecimiento aludido, en el sentido académico, solo puede entenderse desde el litoral de la vocación, canalizada por dos vertientes, la docente y la investigadora. Desde mis tiempos de estudiante en la UASD me di cuenta que me gustaba aclarar dudas a mis compañeros de estudio, y también disfrutaba resolviendo problemas difíciles que eran retadores; incluso hacía pequeñas investigaciones relativas a temas de clases, sin resultados trascendentes, pero que tuvieron la virtud de despertar en mí el gusto por la investigación. 
¿Cómo surgen sus inquietudes por las ciencias y cuáles fueron sus primeros pasos para satisfacerlas?

Como acabo de decir, esas inquietudes comenzaron cuando era estudiante, digamos que eran incipientes, pero se manifestaron con fuerza a través de mi labor docente en la PUCMM en el decenio de los años 70's del siglo pasado, y todo comenzó con un problema de Física Eléctrica planteado por uno de los profesores; había que calcular la resistencia eléctrica de un conductor esférico entre los extremos de su diámetro.

Al principio se pensaba que la solución era sencilla, pero no fue así. Pude resolverlo, la solución consistió en una serie infinita de polinomios de Legendre y dio origen a un artículo que se publicó en el Anuario de la Academia de Ciencias de la República Dominicana del año 1976. Luego siguieron otras investigaciones y otros artículos.

\section{Según su opinión, ¿a dónde debe enfocarse la} enseñanza de las Ciencias Básicas?

Esa enseñanza ha de focalizarse en principios y razonamientos en todas las actividades de formación del estudiante: resolución de problemas para afianzar la base teórica, prácticas de laboratorio para desarrollar destrezas experimentales, exposiciones orales y escritas para desarrollar habilidades comunicacionales e investigación para cultivar y "vivenciar" la ciencia.

Puede extrañar que haya incluido la investigación como una componente importante de la enseñanza de las ciencias, pues en estos tiempos conspira contra ella la excesiva carga asignatural de los estudiantes y la cortedad del período académico.

En las últimas décadas del siglo pasado existían, a mi parecer, mejores condiciones para ello. Recuerdo muy bien que la revista MAGISTER de Física y Matemática (1976-1982) de la PUCMM, fundada y dirigida por el Dr. Eduardo Luna y por mí, servía de medio a los estudiantes para publicar investigaciones sencillas relativas a temas vistos en las clases, motivados por sus profesores.

¿Cuáles son sus aportes más significativos en cuanto al desarrollo curricular de la Universidad?

Según la pregunta existirían también las poco significativas. No sé si entre las siguientes se han colado algunas de éstas últimas:
Entiendo que la publicación de la recientemente mencionada revista MAGISTER es una de ellas. Durante seis años fue un medio de canalización no solamente de inquietudes académicas intelectuales relacionadas con la docencia, sino, también, de inquietudes artísticas con su sección POEMAS FÍSICO-MATEMÁTICOS.

En ese tiempo, quien les habla había iniciado un movimiento poético con ese nombre que tuvo algunos seguidores entre el estudiantado. Escuchen estos versos, seleccionados del poema Incógnitas de Guillermo Torres Corsino:

"¡Yo he visto cosas raras en esta vida! / he visto correr las negativeces / de los electrones/ electrizantes, / haciendo electricidad ante / mis ojos moribundos;/ transitando de goces y verdades, / recorriendo sobre / el verde apizarronado;/ haciéndose tangibles/ por la blancura / de la tiza enamorada; / de la tiza taciturna / y callada."

Estos versos son extraños, ¡una tiza enamorada! ¿Podría mostrarnos un poema de su autoría?

Con mucho gusto. El titulado Lluvia numérica, es uno de los más raros, y está calzado, ¡vaya curiosidad!, con una bibliografía:

$1 \times 9+2=11 \quad$ nube nueve sube mueve llueve $12 \times 9+3=111$ nueve sube mueve llueve nube $123 \times 9+4=1111$ mueve llueve nube nueve sube $1234 \times 9+3=11111$ llueve nube nueve sube mueve Bibliografía: /E. Condon; Curiosities of Mathematics / Haldeman-Julius Company, / Kansas, U.S.A., 1925

Siguiendo con el desarrollo curricular, en el año 1982 el Dr. Eduardo Luna Ramia y quien les habla, preparamos un libro patrocinado por la UNESCO, de Módulos de interrelación de Física y Matemática en la Enseñanza Secundaria.

Más tarde, en la década de los ' 90 , se me ocurrió escribir un libro de texto para la asignatura Física General II adaptado a los estudiantes de Ingeniería, pues entendía que el de Resnick-Halliday que se utilizaba entonces, aunque era muy bueno, había sido escrito para estudiantes estadounidenses. Puse manos a la obra y en el año 1994 salió a la luz con el título Electricidad y Magnetismo. 
Estuve impartiendo por unos 26 años las Físicas Generales II y III; no tuve la oportunidad de escribir un libro de texto para la Física General III, pero al menos preparé, en colaboración con el Prof. Nikolay Polozhaev, un Manual de Laboratorio de Física General III (1992), para las prácticas de laboratorio de los estudiantes de esa asignatura.

En el 1996 viajé a Francia a hacer un entrenamiento en Física Radiológica en el Instituto Gustave Roussy, y a mi regreso un año después me encontré con la novedad de que los estudiantes de Medicina debían cursar dos Físicas antes de entrar a carrera y había que elaborar los programas de teoría y laboratorio de ambas; es decir, cuatro en total.

Esa encomienda me fue asignada por la profesora Rosario Granados, directora del Departamento de Ciencias Básicas en ese entonces, y fue cumplida a su debido tiempo. Aunque empecé a escribir los textos teóricos para ambas Físicas, y circunstancias adversas no me han permitido terminarlos, sí pude preparar los manuales de laboratorio correspondientes a ellas, publicadas las primeras ediciones en el año 2000.

Entre las actividades más recientes figuran un taller de MatLab (software de matemáticas avanzadas) para los profesores de Física y Matemática del Departamento de Ciencias Básicas, impartido en agosto del 2016, y la ponencia titulada Recursos teatrales en la enseñanza de la física leída en el panel "Enseñanza de las ciencias en el siglo XXI", celebrado como parte del evento La Educación en Ciencias en el Siglo XXI, organizado por la PUCMM, en colaboración con la Academia de Ciencias de la República Dominicana y la participación de miembros de la Red Interamericana de Academias de Ciencias.

Es posible que haya más aportes al desarrollo curricular, pero aquí me detengo por razones de espacio.

\section{¿Cuáles entiende usted que serían los cometidos de nuestra Universidad para lograr incentivar a los docentes a la investigación científica?}

Lo primero, crear las condiciones para la incentivación y esto depende del tipo de investigación. Si la Universidad pretende que un docente produzca investigaciones que se publiquen en revistas indexadas (eso he escuchado últimamente), su carga docente debe ser reducida en un porcentaje importante; en algunos casos, en un $50 \%$, en otros en un $100 \%$, dependiendo de las exigencias del trabajo de investigación. Nunca en un $0 \%$; es decir, con la carga docente completa.
En el último tercio del siglo pasado había entre los profesores un ambiente de romanticismo; algunos, como el que les habla, investigaban con su carga completa y aún antes de que existiera el Centro de Investigación (1975). Era una pasión vocacional, si me permiten la expresión. Con la creación de este Centro, la Universidad dio apoyo institucional a las labores investigativas y fueron muchos los proyectos patrocinados por él, el cual, en el año 1987, con motivo de celebrar la PUCMM sus primeros 25 años de existencia, celebró dos jornadas de exposiciones orales y documentales donde mostró los muchos frutos logrados durante ese tiempo.

Si se desea resultados de calidad, hay que costearlas. Algunos proyectos son tan costosos que la Universidad no tiene la capacidad económica para respaldarlos, pero felizmente existe ahora el Ministerio de Educación Superior, Ciencia y Tecnología, (MESCyT) que está ayudando con el financiamiento de proyectos de investigación institucionales. Así está ocurriendo en estos momentos con dos de ellos en nuestro Departamento de Ciencias Básicas.

La cuestión esencial es la siguiente: en una Universidad, los docentes deben estar comprometidos con actividades de investigación, y esto me trae a la memoria una afirmación del filósofo José Ortega y Gasset que he repetido muchas veces ( $n$ veces, como dirían los matemáticos): "La ciencia es la dignidad de la Universidad; más aún -porque, al fin y al cabo, hay quien vive sin dignidad-es el alma de la Universidad, el principio mismo que le nutre de vida e impide que sea sólo un vil mecanismo".

Es decir, la Universidad debe vivir en esa atmósfera, respirar su oxígeno, y a mi entender, eso no se logra únicamente con investigaciones destinadas a revistas indexadas. Estudiantes y docentes pueden muy bien oxigenarse de esa manera con proyectos menos ambiciosos que los de indexación, que, sin duda, son los que proyectan una sólida fortaleza institucional en todos los medios.

En un trabajo publicado y leído aquí y allá titulado El reto de la investigación científica, me refiero a los tres planos (A, $B, C$ ) en los que puede accionar la curiosidad científica. En la A se descubren nuevos principios (candidatos al premio Nobel); en la B se exploran, con principios conocidos, parcelas aún desconocidas y en la $\mathrm{C}$ se trabaja haciendo, citándome a mí mismo: "originales comparaciones (sea con la realidad, sea con otras parcelas), coloreando las exposiciones magistrales con imágenes pintorescas, profundizando y extendiendo el conocimiento personal con la frecuentación a la literatura correspondiente". 
Los resultados de los planos A y $\mathrm{B}$ son los destinados a las revistas indexadas, los de la $\mathrm{C}$ caben en publicaciones menos relevantes (periódicos, revistas, internet) y es en este plano donde hay que motorizar las inquietudes de investigación de estudiantes y docentes que por impedimentos eventuales no puedan moverse en los otros planos, con la muy positiva consecuencia de que las actividades $C$ incidirían enormemente en el desarrollo curricular. Además, a los profesores que tienen la capacidad de moverse en los planos A y B, se les pediría, en razón de su condición de docentes, aplicar las normas que rigen en el $\mathrm{C}$.

En todos estos casos, hay factores que desfavorecen la incentivación. En cuanto al estudiante, el exceso de carga, de créditos académicos, no les deja tiempo para investigar. En cuanto al profesor, una remuneración insuficiente para mantener a su familia, viéndose forzado a dar clases por asignatura adicionadas a su carga completa o a buscar entradas complementarias marginales.

\section{¿Cuál es la importancia de la publicación científica para un académico?}

Primero, aumenta su autoestima; segundo, lo pone en contacto con la comunidad de investigadores especializados en su campo de investigación; tercero, posibilita su participación en congresos internacionales, si la publicación aparece en revistas indexadas.

¿Qué consejos puede dar a los profesores para balancear su desarrollo disciplinar, pedagógico y a la vez, dedicarse a la investigación científica?

El consejo general sería que distribuya con la mayor racionalidad posible el tiempo de que disponga y para eso se necesita orden y disciplina. El desarrollo disciplinar depende más bien de él; si no lo atiende, se estanca, no se actualiza. Respecto a la carga docente, está obligado a atenderla y para hacerlo bien, no solamente necesita su buena disposición, sino condiciones que la favorezcan y esto depende en parte de la Universidad.

En cuanto a la investigación, convendría mucho que la hiciera para la profundización de sus conocimientos y su proyección profesional.

Lo ideal sería que tenga tiempo holgado para sostenerse en ese trípode, de manera que su desempeño académico sea distendido, sin tensiones estresantes. Sin embargo, la realidad tiende a conspirar contra este deseo, obligada generalmente por razones económicas.
La investigación de calidad requiere concentración, tiempo y dinero. Felizmente, con el patrocinio del MESCyT se puede conseguir ayuda financiera para tal fin y conviene aprovechar esta oportunidad, como lo hacen actualmente varios profesores de Ciencias Básicas. En estos casos, la Universidad, vía el departamento correspondiente, ha de asignar al profesor una carga docente que no se convierta, por excesiva, en una fuerza de fricción contraproducente.

De ese modo el profesor podrá balancear como Dios manda las cargas correspondientes a las tres patas del trípode de su pregunta, evitando así fatigas y roturas en ellas.

Usted ha sido director académico en varias ocasiones. Según su experiencia, ¿podría decirnos qué competencias debe desarrollar un director académico?

Más bien competencias requeridas, algunas a desarrollar, entre estas las administrativas, las que no se tienen cuando se ocupa el cargo la primera vez: la eficiente planificación de los periodos académicos, manejo emocionalmente equilibrado y respetuoso de las relaciones con los profesores, los estudiantes, el personal de servicio y las altas instancias de la Universidad.

El director debe tener conciencia de su responsabilidad de la buena marcha del departamento, tanto en el aspecto administrativo como en el académico; se ve sometido a presiones desde arriba y desde abajo y ha de tener la fuerza de carácter para defender su gestión de esas presiones, evitar convertirse en una marioneta.

Un aspecto importante consiste en manifestar autoridad en todo lo que hace, ejercida con sentido de justicia, lo que no impide que sea amable y promueva el buen entendimiento entre todos. Lo más deseable es que tenga madera de líder empático que despierte deseos de imitación de sus valores personales, de su integridad. El decir esto me hace recordar un comentario encontrado en la biografía que escribió el Dr. Gregorio Marañón sobre el emperador romano Tiberio; según ese comentario, el subordinado termina comportándose como su jefe, en lo bueno y en lo malo, salvo, agregaría yo, honrosas excepciones.

Sobra decir que debe ser intelectualmente competente y un profesional de al menos una de las ciencias ofrecidas por su departamento, si se ofrecen varias, como ocurre con el de Ciencias Básicas y, además, conocer bien la Universidad, su filosofía, su misión y sus metas. 